\title{
Determination of Bisphenol A in Paper Products by Synchronous Fluorescence Spectroscopy and Estimation of Daily Exposure
}

\author{
Matheus Gallimberti, ${ }^{a}$ Bruno A. Rocha, ${ }^{\circledR b}$ Vanessa C. O. Souza, ${ }^{a}$ Andres D. Campiglia ${ }^{c}$ \\ and Fernando Barbosa $\mathrm{Jr}$. ${ }^{\circledR} * a$ \\ ${ }^{a}$ Laboratório de Toxicologia e Essencialidade de Metais, \\ Faculdade de Ciências Farmacêuticas de Ribeirão Preto, Universidade de São Paulo, \\ 14049-903 Ribeirão Preto-SP, Brazil \\ ${ }^{b}$ Instituto de Ciências Ambientais, Químicas e Farmacêuticas, Universidade Federal de São Paulo, \\ Rua Prof. Artur Riedel, 275, 09972-270 Diadema-SP, Brazil
}

${ }^{c}$ Department of Chemistry, University of Central Florida, 32816 Orlando, Florida, USA

\begin{abstract}
In this study, a simple and fast procedure was developed and validated for the determination of bisphenol A (BPA) in paper products using synchronous fluorescence spectroscopy. The method was used for the determination of BPA in thirteen types of paper products, including thermal receipt papers, lottery tickets, bus tickets, business cards, mailing envelopes, flyers, napkins, printing paper, food contact paper, kitchen rolls, toilet paper, newspapers, and magazines. BPA was found in $98 \%$ of thermal receipt papers $(n=341)$ at concentrations ranging from below the limit of quantification (LOQ) to $27.7 \mathrm{mg} \mathrm{g}^{-1}$ with a geometric mean of $14.6 \mathrm{mg} \mathrm{g}^{-1}$ and a median of $17.7 \mathrm{mg} \mathrm{g}^{-1}$. The detection rate for other paper products was $96 \%$, with BPA concentrations ranging from below the LOQ to $379 \mu \mathrm{g} \mathrm{g}^{-1}$ and a median of $17.3 \mu \mathrm{g} \mathrm{g}^{-1}$. The estimated daily intake for the adjusted bodyweight of BPA (calculated at median concentrations) through dermal absorption from handling papers was 14.5 and $1070 \mathrm{ng} \mathrm{day}^{-1}$ for the general population and occupationally-exposed individuals, respectively. The proposed analytical method is simple, fast, and cost-effective for the determination of BPA in paper samples. Moreover, an estimated daily exposure of Brazilians to BPA through dermal absorption from handling different types of papers is shown.
\end{abstract}

Keywords: bisphenol A, endocrine disruptor, synchronous fluorescence, paper, exposure, daily intake

\section{Introduction}

Bisphenol A (BPA) is one of the highly produced chemicals globally in terms of volume, with over six billion pounds being produced every year worldwide. ${ }^{1}$ It is primarily used as a monomer in the production of polycarbonate and epoxy resins. Polycarbonate is used in the production of a variety of consumer products, including recyclable packaging for food and beverage storage, sports equipment, medical devices, dental fillings, and household equipment. On the other hand, epoxy resins are mainly used as a protective lining for canned foods and beverages. ${ }^{2}$ Another important application of BPA is in the production of thermal papers. They have several commercial applications, including point of sale receipts, labels, and tickets. ${ }^{2}$

*e-mail: fbarbosa@fcfrp.usp.br
BPA is considered an endocrine disruptor because it interferes with the hormonal system by different mechanisms, promoting a series of adverse effects in women such as infertility, polycystic ovary syndrome, endometriosis, spontaneous abortions, and breast cancer. ${ }^{3}$ In men, BPA reduces male sexual function, sperm quality, testosterone levels, and sperm count. ${ }^{3} \mathrm{BPA}$ also plays an important role in the etiology of chronic diseases such as type 2 diabetes, cardiovascular diseases, congenital problems, behavioral disorders, hypertension, altered renal function, and obesity. ${ }^{3,4}$ Human beings are exposed to BPA from multiple sources, including water, soil, dust, food, and beverages..$^{4-9}$ Among these sources, the human diet is the main route of exposure. ${ }^{10,11}$ Geens et al. ${ }^{12}$ determined BPA concentration in 45 canned beverages and 21 canned food items from the Belgian market. Using detailed information from the Belgian food consumption 
survey, the BPA intake of adults through canned foods and beverages was estimated to be $1050 \mathrm{ng}$ day $^{-1}$. However, an important route of exposure that is currently being studied is dermal absorption. Some studies have shown that BPA can also be absorbed at a rate of $27 \%$ via the skin while handling certain kind of papers, ${ }^{2,13-16}$ especially thermal papers, which have high concentrations of BPA. ${ }^{15-20}$ In another study, Geens et al. ${ }^{16}$ determined BPA concentration in 44 thermal paper samples collected in Belgium. BPA was detected in all the samples; $73 \%$ of the samples had concentrations between 0.9 and $2.1 \%$. An estimation of human exposure through thermal paper results in a median intake of $445 \mathrm{ng} \mathrm{BPA} \mathrm{day}{ }^{-1}$ for the general population.

Thus, thermal papers are potential sources of human exposure to BPA. They can also contaminate other types of papers; this is because BPA can be introduced into the paper production cycle, and approximately $30 \%$ of the thermal paper produced enters the recycling process. ${ }^{21}$ According to a study by Gehring et al., ${ }^{22}$ some of these papers may have high concentrations of BPA, such as in toilet paper and waste paper, which exhibit a range of 2 to $430 \mathrm{mg} \mathrm{kg}^{-1}$ (100\% recycled) and 0.093 to $9.1 \mathrm{mg} \mathrm{kg}^{-1}$, respectively. Besides, BPA present in thermal papers can be transferred to other types of papers, contaminating them every time they come into contact with each other or are handled together. An example is the study by Liao and Kannan, ${ }^{2}$ where the authors showed that BPA were found in paper currencies from several countries due to the contact with thermal papers inside of the wallets and bags. ${ }^{2}$

Despite the frequent use of liquid chromatography coupled with mass spectrometry (LC-MS/MS) for the determination of BPA in paper samples, the high concentrations generally found in the order of $\mu \mathrm{g} \mathrm{g}^{-1}$ to $\mathrm{mg} \mathrm{g}^{-1}$, suggest that there is no need for a highly sensitive and relatively costly technique to monitor this analyte, especially in paper products. In this article, we take advantage of the inherent fluorescence of BPA to develop a simple and low cost approach for its routine determination in numerous paper samples.

Due to its inherent weak emission at room temperature, the analysis of BPA at trace concentration levels via roomtemperature fluorescence (RTF) spectroscopy has been attempted with the aid of fluorescence enhancer solvents such as ionic liquids ${ }^{23}$ or fluorescence quenching probes. ${ }^{24}$ Another limitation of RTF spectroscopy for the direct analysis of BPA, i.e., no chromatographic separation, is the broad nature of excitation and emission spectra that lead to spectral interference from sample concomitants. Although spectral interference can be avoided by high-performance liquid chromatography (HPLC), ${ }^{25,26}$ the chromatographic separation increases analysis time and cost for the routine analysis of numerous samples.

Numerous approaches exist to reduce overlapping of excitation and fluorescence spectra. These include reducing the sample temperature, ${ }^{27}$ time-resolution of fluorescence decays ${ }^{28}$ and processing multidimensional data formats with chemometric algorithms. ${ }^{29,30}$ The approach we present here is based on constant energy synchronous fluorescence spectroscopy (CESFS). CESFS reduces spectral interference by recording fluorescence spectra at a constant wavelength offset $(\Delta \lambda)$ between excitation $(\lambda$ exc) and emission ( $\lambda$ em) wavelengths. This dual wavelength dependence introduces the wavelength offset as a new selectivity parameter which is susceptible to optimization for spectral simplification and minimization, or ideally elimination, of spectral interference. By using a wavelength offset of $85 \mathrm{~nm}$, we demonstrate the feasibility of directly determining BPA in contaminated paper samples with no need for previous chromatographic separation.

\section{Experimental}

\section{Chemical and reagents}

The analytical standard of BPA (> 99\% purity) was obtained from Sigma-Aldrich (Saint Louis, USA), and methanol (MeOH) solvent was purchased from J. T. Baker (Phillipsburg, USA). High purity deionized water (Millipore RiOs-DITM, Bedford, USA) was used for all the experiments.

\section{Sampling}

Thermal receipt paper samples $(\mathrm{n}=341)$ were collected from different locations, including the local supermarkets, restaurants, banks, and stores, among others. Other papers and paper products analyzed $(n=103)$ included flyers, magazines, newspapers, bus tickets, lottery tickets, mailing envelopes, food contact papers, business cards, printing paper, paper towels, paper napkins, and toilet paper. These samples were collected mainly in São Paulo State, Brazil.

\section{Extraction procedure}

BPA was extracted from the paper samples following a previously reported method ${ }^{18}$ with some modifications. Briefly, a circular spot (diameter: $12 \mathrm{~mm}$ ) was cut from the middle of each paper using a punching machine. After accurately weighing each circular spot (ca. 7-8 mg), it was cut in small pieces and transferred into a $15 \mathrm{~mL}$ polypropylene conical tube. Next, $5 \mathrm{~mL}$ of $\mathrm{MeOH}$ was 
added to the sample. The mixture was shaken in a vortex mixer (Vortex QL-901, Biomixer, California, USA) for $60 \mathrm{~s}$ and ultra-sonicated (Ultrasonic cleaner 2840D, Odontobras, Ribeirão Preto, Brazil) for $10 \mathrm{~min}$. The mixture was then centrifuged at $4500 \times \mathrm{g}$ for $3 \mathrm{~min}$ (Centribio 80-2B, Biovera, Rio de Janeiro, Brazil), and $100 \mu \mathrm{L}$ aliquots were transferred to other tubes and diluted for fluorescence analysis. These solutions were stored at $-20^{\circ} \mathrm{C}$, and before instrumental analysis, the aliquot was filtered through a $0.45 \mu \mathrm{m}$ syringe filter.

\section{Instrumental analysis}

The quantitative determination of BPA was performed with a spectrofluorometer (LS 55, PerkinElmer, Waltham, USA). The light source was a xenon discharge lamp, equivalent to $20 \mathrm{~kW}$ for $8 \mu$ s duration. The detection occurs through a photomultiplier model R928 (Red-Sensitive) and can be optionally fitted for operation up to $900 \mathrm{~nm}$. The selection of the wavelengths was carried out using Monk-Gillieson type monochromators, which cover the 200-800 $\mathrm{nm}$ range for excitation and 200-900 $\mathrm{nm}$ range for emission. The excitation (2.5-15.0 nm) and emission $(2.5-20.0 \mathrm{~nm})$ slits can be varied and selected in $0.1 \mathrm{~nm}$ increments. It has a scanning speed of $10-1500 \mathrm{~nm} \mathrm{~min}^{-1}$ and can be selected in $1.0 \mathrm{~nm}$ increments. The sensitivity of the equipment is evident from the signal to noise (500:1 root-mean-square) ratio, using the Raman band of water with excitation at $350 \mathrm{~nm}$, and excitation and emission bandpass at $10 \mathrm{~nm}$. In the determination of BPA by constant-wavelength synchronous fluorescence spectroscopy, the following conditions were employed: excitation slit width of $5.0 \mathrm{~nm}$; emission slit width of $5.0 \mathrm{~nm}$; wavelength range of 200-400 nm; scan rate of $1500 \mathrm{~nm} \mathrm{~min}^{-1}$. The BL Studio version 1.04.02 (Biolight Luminescence Systems Ltd.) software was used to control the instrument and process data.

\section{Quality assurance and quality control}

For every batch of 40 samples, a procedural blank, a spiked blank, a pair of matrix spiked samples, and duplicate samples were analyzed. The procedural blanks (containing $\mathrm{MeOH}$ in place of paper sample) were processed exactly similar to samples as a check for interferences or contamination. BPA was not found in procedural blanks. The recoveries of BPA from spiked blanks and different types of spiked matrices ranging from $96 \pm 11 \%$ to $112 \pm 8 \%$ (mean \pm standard deviation (SD)), respectively. The relative standard deviation of replicate analysis of different kind of paper samples was $<15 \%$. Instrumental drift in sensitivity was checked by analyzing a midpoint calibration standard after every 40 samples. Instrumental calibration was verified by injecting calibration standards $(n=10)$, ranging in concentrations from 25 to $450 \mu \mathrm{g} \mathrm{L}^{-1}$ of BPA in methanol.

\section{Results and Discussion}

\section{General aspects}

The emission and excitation spectra of BPA and possibly interfering bisphenol S (BPS) were recorded from individual standard solutions in methanol. Their concentrations $\left(0.5 \mathrm{mg} \mathrm{L}^{-1}\right.$ of BPA and $1.0 \mathrm{mg} \mathrm{L}^{-1}$ of BPS) were within the linear dynamic ranges of the calibration curves obtained at the maximum excitation and fluorescence wavelength of each compound. All spectra are shown in Figure 1. The two excitation bands of BPA with maximum intensities at 230 and $280 \mathrm{~nm}$ possible refer to $\mathrm{S} 0 \rightarrow \mathrm{S} 2$ and $\mathrm{S} 0 \rightarrow \mathrm{S} 1$ absorption transitions. Excitation of $\mathrm{BPA}$ at $230 \mathrm{~nm}$ produces fluorescence emission of $\mathrm{S} 1 \rightarrow \mathrm{S} 0$ with maximum excitation at $310 \mathrm{~nm}$. The spectrum of BPS shows single excitation and fluorescence bands with maximum wavelengths at 260 and $328 \mathrm{~nm}$, respectively. These bands can be attributed to the excitation and the radiative de-activation of the first singlet excited state.

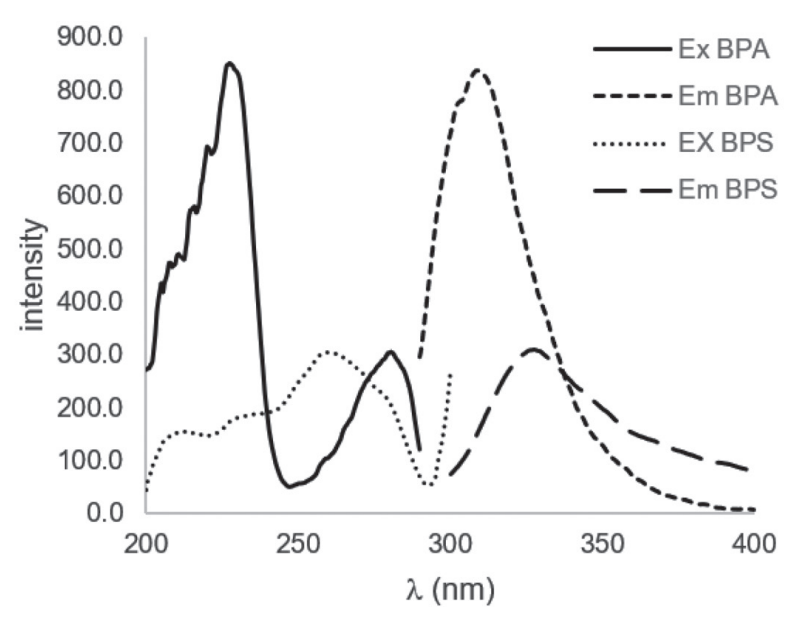

Figure 1. Excitation (Ex) and emission (Em) spectra of BPA and BPS.

Since BPS shows residual fluorescence at $310 \mathrm{~nm}$ upon excitation at $230 \mathrm{~nm}$, the possibility of selective excitation of BPA at $230 \mathrm{~nm}$ exists, mainly if a narrower spectral band-pass were to be used for sample excitation. Instead of further exploring this possibility, we investigated the CESFS approach. Figure 2 shows the synchronous fluorescence of BPA and BPS recorded with an $85 \mathrm{~nm}$ wavelength offset $(\Delta \lambda=85 \mathrm{~nm})$. Among the range of wavelength offsets tested (200-800 nm), this $\Delta \lambda$ provided 
the best spectral differentiation between BPA and BPS and the highest BPA/BPS instensity ratio. The maximum synchronous fluorescence wavelengths of BPA and BPS appear at 321.5 and $355 \mathrm{~nm}$, respectively. This wavelength offset was then used for all further experiments.

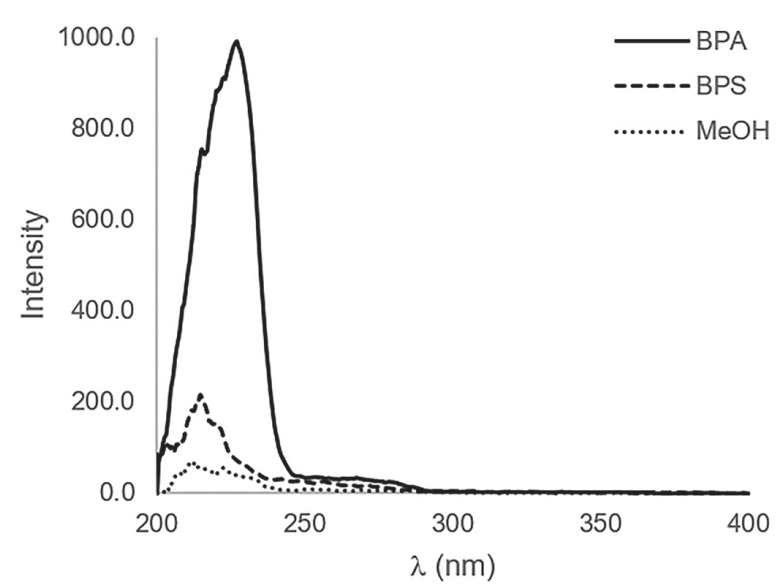

Figure 2. Synchronous excitation spectra of BPA and BPS in terms of the difference in wavelengths $(\Delta \lambda)=85 \mathrm{~nm}$.

\section{Method performance}

A linear response (correlation coefficient $(r)=0.9993)$ was observed from 25 to $450 \mu \mathrm{g} \mathrm{L} \mathrm{L}^{-1}$ of BPA in methanol, according to the equation $\mathrm{F}=(2.0849 \pm 0.0575) \mathrm{C}_{\mathrm{BPA}}+$ (16.5617 \pm 3.0879$)$, F being the synchronous fluorescence intensity, and $\mathrm{C}_{\mathrm{BPA}}$ referring to the analyte concentration in $\mu \mathrm{g} \mathrm{L}^{-1}$. The limits of detection (LOD) and quantification (LOQ) were estimated as $1.20 \pm 0.68 \mu \mathrm{g} \mathrm{L}^{-1}$ and $3.99 \pm 2.26 \mu \mathrm{g} \mathrm{L}^{-1}$, respectively, using the equation: $\mathrm{LOD}=3 \mathrm{SB} / \mathrm{m}$ and LOQ $=10 \mathrm{SB} / \mathrm{m}$, where $\mathrm{SB}$ is the standard deviation of 30 blank determinations and $\mathrm{m}$ is the slope of the calibration curve. The precision of the method was evaluated in terms of repeatability and reproducibility, expressed as precision within one day (intra-day) and reproducibility between days (inter-day) by the relative standard deviations (RSD). The obtained precision values were lower than $10 \%$, while the accuracy values ranged from 87 to $111 \%$ (expressed as percentage recovery). The selectivity of proposed method was evaluated by comparing the slope (a) of analytical curves, one in the presence of different kinds of the matrix (different kind of papers) and the other without the matrix (solvent). The slopes of the calibration curves obtained by the least squares method were statisticall equivalent ( $p>0.05, t$-test) in all cases. The same is true for the analysis of 30 randomly selected paper samples. The BPA concentrations obtained via CESFS were statistically equivalent ( $t$-test, 95\%) to those obtained via previously published LC-MS/MS methodology. ${ }^{18}$
The method also showed good linear response and selectivity, low values of LOD and LOQ, and high accuracy and precision. Thus, the method is a useful tool for routine analysis of BPA in paper samples.

\section{Application}

\section{Thermal receipt papers}

The developed method was applied for the analysis of 341 thermal receipt paper samples. BPA was detected in 98\% of the analyzed samples, at concentrations ranging from below the LOQ to $27.7 \mathrm{mg} \mathrm{g}^{-1}$ with a geometric mean (GM) of $14.6 \mathrm{mg} \mathrm{g}^{-1}$ and a median of $17.7 \mathrm{mg} \mathrm{g}^{-1}$ (Table 1). Among the 341 samples analyzed, BPA was not detected in seven samples ( $2 \%$ of the total), which suggests the existence of alternatives, among them possibly BPS, which has been used as a developer in some types of thermal papers. ${ }^{31}$ High BPA concentrations were detected (Table 1) on all types of thermal receipt papers (bank card receipts, bank account, and cash register receipts), suggesting that the general population may be exposed to BPA.

The concentrations of BPA determined by our technique were compared with those reported in studies conducted in different countries, except in Japan, that concentrations were below the LOD (Table 2). Overall, the BPA concentrations around the world ranged from 44 to $100 \%$, with values below the detection limit of the method up to $4.3 \%$ ((mg BPA) (100 mg paper $\left.)^{-1}\right)$. In this study, BPA was detected in thermal papers with detection frequencies of $98 \%$, and the concentration was up to $2.8 \%$, the higher concentration found in other countries (Table 2).

\section{Paper and paper products}

BPA present in thermal papers is not chemically bound. It exists as a free monomer and can be easily transferred from thermal papers to other types of paper. ${ }^{13,17}$ Besides, the process of recycling thermal papers can be considered as a potential source of BPA contamination for recyclable paper and paper products, as nearly $30 \%$ of the global thermal receipt paper enters the recycling process. ${ }^{21}$ Recycled papers are used in the production of a wide variety of paper products such as toilet paper, paper towels, newspapers, and magazines, among others. ${ }^{19}$ The process of recycling thermal receipt papers with other types of paper may increase the risk of human exposure to BPA via cross-contamination. In this study, 103 samples of twelve different paper types were analyzed, and BPA was detected in $96 \%$ of the analyzed samples in concentrations ranging from below the LOQ to $379 \mu \mathrm{g} \mathrm{g}^{-1}$ with a GM of $14.7 \mu \mathrm{g} \mathrm{g}^{-1}$ and a median of $17.3 \mu \mathrm{g} \mathrm{g}^{-1}$ (Table 3). Figure 3 represents the BPA concentrations (GM) in various types of papers. 
Table 1. BPA concentration in different thermal papers according to their source locations

\begin{tabular}{|c|c|c|c|c|c|c|}
\hline Thermal paper & Location & $\mathrm{n}$ & $\mathrm{GM} /\left(\mathrm{mg} \mathrm{g}^{-1}\right)$ & Median / $\left(\mathrm{mg} \mathrm{g}^{-1}\right)$ & Range / $\left(\mathrm{mg} \mathrm{g}^{-1}\right)$ & Detection rate / \% \\
\hline Cash register & airplane ticket & 6 & 19.1 & 18.5 & $16.5-22.2$ & 100 \\
\hline Cash register & bus ticket & 6 & 3.26 & 21.3 & $0.033-24.2$ & 100 \\
\hline Cash register & cinema & 6 & 19.8 & 20.3 & $17.5-22.3$ & 100 \\
\hline Cash register & candy store & 6 & 4.52 & 13.0 & $0.112-26.7$ & 100 \\
\hline Cash register & drugstore & 22 & 10.5 & 19.5 & $0.029-23.0$ & 100 \\
\hline Cash register & bookshop & 7 & 19.5 & 21.8 & $13.0-25.5$ & 100 \\
\hline Cash register & clothing store & 10 & 21.0 & 20.0 & $13.7-26.1$ & 90 \\
\hline Cash register & fragrance store & 6 & 2.99 & 17.2 & $0.054-24.2$ & 100 \\
\hline Cash register & fuel station & 15 & 11.9 & 19.1 & $0.567-27.0$ & 93.3 \\
\hline Cash register & restaurant & 30 & 12.8 & 18.5 & $0.880-25.0$ & 100 \\
\hline Cash register & supermarket & 33 & 16.7 & 19.0 & $<$ LOQ-25.6 & 90.9 \\
\hline Cash register & others & 14 & 18.0 & 20.0 & $10.7-22.3$ & 85 \\
\hline Bank account & banks & 11 & 17.8 & 18.4 & $13.7-22.8$ & 100 \\
\hline Toll register & toll bridge & 10 & 17.4 & 16.8 & $14.3-27.8$ & 100 \\
\hline Bank card & bar & 20 & 16.6 & 16.6 & $13.2-21.9$ & 100 \\
\hline Bank card & fast-food restaurant & 30 & 17.4 & 17.3 & $13.9-23.4$ & 100 \\
\hline Bank card & drugstore & 15 & 17.4 & 17.6 & $10.2-24.4$ & 100 \\
\hline Bank card & supplement store & 5 & 16.3 & 17.7 & $8.78-21.1$ & 100 \\
\hline Bank card & fuel station & 9 & 15.3 & 15.4 & $11.1-19.0$ & 100 \\
\hline Bank card & restaurant & 26 & 15.0 & 15.2 & $11.3-19.8$ & 100 \\
\hline Bank card & supermarket & 12 & 19.5 & 19.3 & $14.7-24.2$ & 100 \\
\hline Bank card & others & 13 & 14.3 & 14.0 & $8.95-18.3$ & 100 \\
\hline All thermal papers & - & 341 & 14.6 & 17.7 & $<$ LOQ-27.8 & 98.0 \\
\hline
\end{tabular}

n: number of samples; GM: geometric mean; LOQ: limit of quantification.

Table 2. BPA concentrations in thermal paper receipts worldwide

\begin{tabular}{|c|c|c|c|c|}
\hline Country & $\mathrm{n}$ & Detection rate / \% & $\begin{array}{l}\text { Range / }(\%(\mathrm{mg} \mathrm{BPA}) \\
\left.\quad(100 \mathrm{mg} \text { paper })^{-1}\right)\end{array}$ & Reference \\
\hline Brazil & 341 & 98 & $<$ LOQ-2.8 & this study \\
\hline Brazil & 190 & 98 & $<$ LOQ-4.3 & Rocha et al..$^{18}$ \\
\hline Belgium & 44 & 98 & $<1 \times 10^{-6}-2.1$ & Geens et al..$^{16}$ \\
\hline China & 42 & 100 & $0.3-1.5$ & Lu et al..$^{15}$ \\
\hline Korea & 11 & 100 & $2 \times 10^{-3}-1.0$ & Liao and Kannan ${ }^{19}$ \\
\hline Denmark & 12 & 65 & $<$ LOQ-1.7 & Lassen et $_{\text {al. }} .^{32}$ \\
\hline USA & 83 & 100 & $5 \times 10^{-4}-1.4$ & Liao and Kannan ${ }^{19}$ \\
\hline USA & 36 & 44 & $0.8-2.8$ & 33 \\
\hline USA & 10 & 80 & $0.09-1.7$ & Mendum et al. ${ }^{17}$ \\
\hline Italy & 50 & 88 & $<$ LOQ-1.5 & Russo et al..$^{20}$ \\
\hline Japan & 6 & 0 & $<$ LOQ & Liao and Kannan ${ }^{19}$ \\
\hline Sweden & 16 & 100 & $0.6-2.3$ & 34 \\
\hline Switzerland & 13 & 85 & $<5 \times 10^{-5}-1.7$ & Biedermann et al..$^{13}$ \\
\hline Vietnam & 3 & 100 & $0.6-0.7$ & Liao and Kannan ${ }^{19}$ \\
\hline
\end{tabular}

n: number of samples; LOQ: limit of quantification. 
Table 3. BPA concentrations in various paper samples

\begin{tabular}{|c|c|c|c|c|c|}
\hline Paper type & $\mathrm{n}$ & $\mathrm{GM} /\left(\mu \mathrm{g} \mathrm{g}^{-1}\right)$ & Median / $\left(\mu \mathrm{g} \mathrm{g}^{-1}\right)$ & Range / $\left(\mu \mathrm{g} \mathrm{g}^{-1}\right)$ & Detection ratio / \% \\
\hline Lottery ticket & 7 & 16.5 & 15.9 & $11.6-26.4$ & 100 \\
\hline Bus ticket & 5 & 1.85 & 2.88 & $<$ LOQ-5.56 & 80 \\
\hline Business card & 12 & 21.1 & 22.17 & $7.67-57.0$ & 100 \\
\hline Envelope & 11 & 17.6 & 16.9 & $9.42-55.5$ & 100 \\
\hline Flyer & 10 & 38.1 & 36.0 & $10.6-110$ & 100 \\
\hline Napkins & 8 & 14.0 & 15.3 & $6.11-21.2$ & 100 \\
\hline Newspaper & 6 & 26.7 & 44.5 & $1.15-379$ & 100 \\
\hline Printing paper & 3 & 18.7 & 17.6 & $14.7-25.0$ & 100 \\
\hline Food contact papers & 20 & 12.2 & 17.3 & $2.14-56.1$ & 100 \\
\hline Toilet paper & 8 & 15.5 & 16.8 & $7.16-31.0$ & 100 \\
\hline Paper towels & 4 & 28.4 & 31.0 & $15.0-54.0$ & 100 \\
\hline Magazine & 9 & 2.99 & 7.79 & < LOQ-18.7 & 77 \\
\hline Total (all papers) & 103 & 14.7 & 17.3 & $<$ LOQ-379 & 96 \\
\hline
\end{tabular}

$\mathrm{n}$ : number of samples; GM: geometric mean; LOQ: limit of quantification.

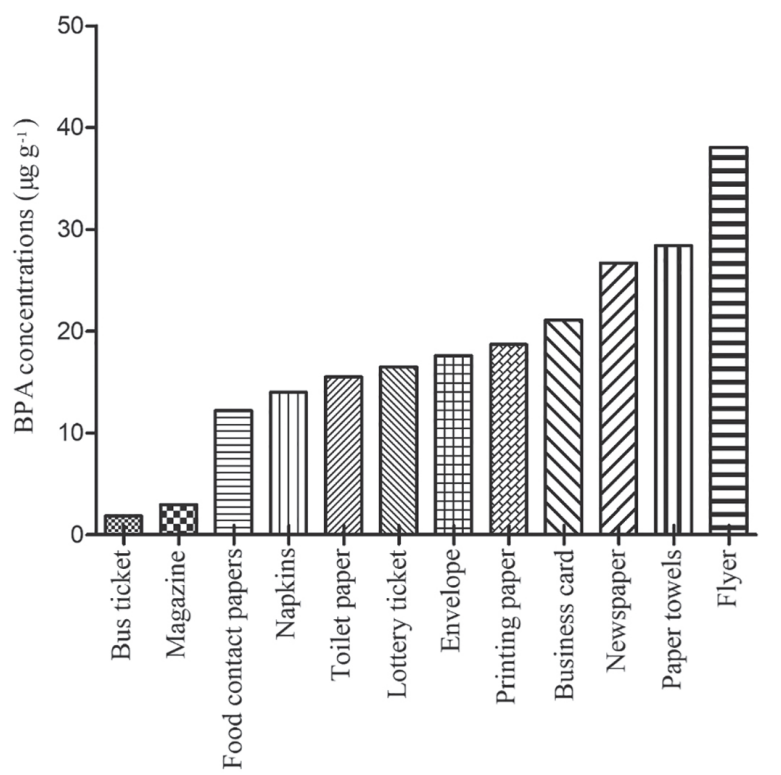

Figure 3. BPA concentrations (geometric mean) in various paper products.

Few studies ${ }^{19,22,31,35}$ have reported the occurrence of BPA in paper and paper products. Vinggaard et al..$^{35}$ collected twenty paper towel samples, of which nine were produced from recycled paper, and the remainder were virgin paper obtained from stores in Denmark. BPA was detected in concentrations of 0.6 to $24.1 \mu \mathrm{g} \mathrm{g} \mathrm{g}^{-1}$ (GM: $3.9 \mu \mathrm{g} \mathrm{g}^{-1}$ ) in the recycled papers, and concentrations below $0.04 \mu \mathrm{g} \mathrm{g}^{-1}$ in the virgin paper, except for one sample that had $0.1 \mu \mathrm{g} \mathrm{g}^{-1}$ of BPA, confirming that recycled paper was responsible for the contamination. The concentrations of BPA found in Denmark were lower but at the same order of magnitude $\left(\mu \mathrm{g} \mathrm{g}^{-1}\right)$ as those found in this study (15.0 to $54.0 \mu \mathrm{g} \mathrm{g}^{-1}$, GM: $\left.28.4 \mu \mathrm{g} \mathrm{g}^{-1}\right)$.
Gehring et al..$^{22}$ analyzed three types of toilet paper made from $100 \%$ recycled paper, and discarded paper (including flyers, magazines, and newspapers) obtained from supermarkets in Germany. BPA was found in all paper samples, with concentrations ranging from 3.2 to $46.1 \mu \mathrm{g} \mathrm{g}^{-1}$ (GM: $18.9 \mu \mathrm{g} \mathrm{g}^{-1}$ ) for toilet paper samples and 0.09 to $5.1 \mu \mathrm{g} \mathrm{g}^{-1}$ (GM: $1.24 \mu \mathrm{g} \mathrm{g}^{-1}$ ) for other paper types. The concentrations of BPA found in toilet paper in this study (7.16 to $31.0 \mu \mathrm{g} \mathrm{g}^{-1}$; GM: $15.5 \mu \mathrm{g} \mathrm{g}^{-1}$, with a detection rate of 100\%) are similar to those obtained by Gehring et al..$^{22}$ In this study, the BPA concentrations found for discarded papers, which include flyers, magazines, and newspapers (<LOQ-379 $\mu \mathrm{g} \mathrm{g}^{-1}$; GM: $16.0 \mu \mathrm{g} \mathrm{g}^{-1}$, with a detection rate of $91 \%$ ) were higher, but in the same order $\left(\mu \mathrm{g} \mathrm{g}^{-1}\right){ }^{21}$ Ozaki et al. ${ }^{36}$ analyzed twenty-eight samples of paper and paperboard used as food packaging, of which twelve were made from recycled material and the others from virgin paper. BPA was detected in $67 \%$ of the analyzed samples $\left(0.19-26.0 \mu \mathrm{g} \mathrm{g}^{-1}\right)$ with concentrations in the range of < LOQ-26.0 $\mu \mathrm{g} \mathrm{g}^{-1}$ (GM: $0.255 \mu \mathrm{g} \mathrm{g}^{-1}$ ) for recycled paper samples and < LOQ-0.36 $\mu \mathrm{g} \mathrm{g}^{-1}$ (GM: $0.044 \mu \mathrm{g} \mathrm{g}^{-1}$ ) for virgin paper samples. The concentrations of BPA found in Brazil (present study) in paper samples in contact with food were 2.14 to $56.1 \mu \mathrm{g} \mathrm{g}^{-1}$ (GM: $12.2 \mu \mathrm{g} \mathrm{g}^{-1}$ ) and are close to those determined by Ozaki et al. ${ }^{36}$ for samples from Japan.

Liao and Kannan ${ }^{19}$ determined the concentration of BPA in 202 samples of fifteen types of paper (thermal paper, flyers, magazines, tickets, envelopes, newspapers, paper in contact with food, food boxes, luggage labels, printing paper, business cards, napkins, paper towels, and toilet paper) collected in different cities of the United States of America. Among the different paper products (excluding 
thermosensitive papers, $\mathrm{n}=103$, whose detection rate was $94 \%), 81 \%$ of the samples $(\mathrm{n}=99)$ contained BPA in concentrations ranging from < LOQ to $14.4 \mu \mathrm{g} \mathrm{g} \mathrm{g}^{-1}$ (GM: $\left.0.016 \mu \mathrm{g} \mathrm{g}^{-1}\right){ }^{19}$

\section{Exposure to BPA via handling of papers}

The exposure of the Brazilian population to BPA via handling of thermal receipt papers and other paper products was evaluated according to the method reported by Liao and Kannan ${ }^{19}$ with some modifications. Little information is available on the transfer rate of BPA through the manipulation of these types of papers in the literature, and this information is not available for Brazilians. Therefore, for the calculation of the estimated daily intakes (EDI), values found by other authors ${ }^{13,31}$ were used. EDI (ng day $^{-1}$ ) of BPA was calculated using the following equation:

$\mathrm{EDI}=\mathrm{K} \times \mathrm{C} \times \mathrm{HF} \times \mathrm{HT} \times \mathrm{AF} / 10^{6}$

where $\mathrm{K}$ is the paper-to-skin transfer coefficient of BPA (calculated by Biedermann et al., ${ }^{13}$ as $21,522.4 \mathrm{ng} \mathrm{s}^{-1}$ ), C is the concentration of BPA in the paper samples $\left(\mu \mathrm{g} \mathrm{g}^{-1}\right)$, $\mathrm{HF}$ is the handling frequency (time day $^{-1}$; for thermal receipt papers, 2 and 150 times day $^{-1}$ for the general population and occupationally-exposed individuals, respectively; for other paper types, 10 times day ${ }^{-1}$ for magazines, newspapers, napkins, paper towels, and toilet paper, and 5 times day $^{-1}$ for lottery ticket, bus ticket, business cards, envelopes, flyers, printing paper, food contact papers, as much for general as for occupationally population exposure times day $^{-1}$ ); HT is the handling time (assumed as $5 \mathrm{~s}$ for each handling); and $\mathrm{AF}$ is the absorption fraction of BPA by skin (27\% according to literature). ${ }^{2}$

The estimated geometric mean and median of daily intakes of BPA through dermal absorption by handling thermal receipt papers for the general population were 850 and 1,027 $\mathrm{ng} \mathrm{day}^{-1}$, and for occupationally-exposed individuals (individuals handling thermal papers frequently, for example, supermarket cashiers) were 63,761 and $77,054 \mathrm{ng} \mathrm{day}^{-1}$, respectively (Table 4). For other types of papers, the geometric mean and median were also estimated and these values are given in Table 4. The estimated geometric mean and median for the total daily intake of BPA ( $\Sigma$ EDI) from all thirteen types of paper products analyzed in this study were 862 and $1,041 \mathrm{ng} \mathrm{day}^{-1}$ for the general population, and 63,733 and 77,068 $\mathrm{ng}^{\text {day }}{ }^{-1}$ for occupationally-exposed individuals, respectively (Table 4). The thermal receipt papers had an extremely high concentration of BPA and contributed the most to dermal exposure to BPA (> 98\%; Table 4). For the calculation of intake adjusted for body weight (bw), the values found were divided by the mean bw of the Brazilian population, which is $72 \mathrm{~kg}$ for adult men (over 20 years), ${ }^{37}$ the values obtained are given in Table 5. Studies carried out in other countries have also reported EDI values similar to those found in this study. Russo et al..$^{20}$ determined BPA concentration in thermal paper receipts collected in Italy from 50 different sources. The value of EDI for general population was $62.5 \mathrm{ng} \mathrm{day}^{-1}$ (mean concentration). Lu et al. ${ }^{15}$ analyzed

Table 4. Estimated daily intake (EDI) of BPA from the manipulation of papers by the general population and occupationally-exposed individuals

\begin{tabular}{|c|c|c|c|c|}
\hline \multirow{2}{*}{ Paper type } & \multicolumn{2}{|c|}{ General population / (ng day ${ }^{-1}$ ) } & \multicolumn{2}{|c|}{ Occupational exposure / (ng day $\left.{ }^{-1}\right)$} \\
\hline & GM & Median & GM & Median \\
\hline Thermal paper & 850 & 1,027 & 63,761 & 77,054 \\
\hline Lottery tickets & 0.959 & 0.925 & 0.959 & 0.925 \\
\hline Bus tickets & 0.108 & 0.167 & 0.108 & 0.167 \\
\hline Business card & 1.23 & 1.28 & 1.23 & 1.28 \\
\hline Envelopes & 1.02 & 0.978 & 1.02 & 0.978 \\
\hline Flyer & 2.22 & 2.09 & 2.22 & 2.09 \\
\hline Napkins & 0.816 & 0.891 & 0.816 & 0.891 \\
\hline Newspapers & 1.55 & 2.59 & 1.55 & 2.59 \\
\hline Printing paper & 1.08 & 1.03 & 1.08 & 1.03 \\
\hline Food contact papers & 0.712 & 1.00 & 0.712 & 1.00 \\
\hline Toilet papers & 0.903 & 0.975 & 0.903 & 0.975 \\
\hline Paper towels & 1.65 & 1.80 & 1.65 & 1.80 \\
\hline Magazines & 0.174 & 0.453 & 0.174 & 0.453 \\
\hline Total exposure ( $\Sigma$ EDI) & 862 & 1,041 & 63,773 & 77,068 \\
\hline
\end{tabular}

GM: geometric mean. 
Table 5. Estimated daily intake (EDI) adjusted for body weight ( $72 \mathrm{~kg}$ ) of BPA from the manipulation of papers by the general population and occupationallyexposed individuals

\begin{tabular}{lcccc}
\hline \multirow{2}{*}{ Paper type } & \multicolumn{2}{c}{ General population $/\left(\mathrm{ng} \mathrm{kg}^{-1} \mathrm{bw} \mathrm{day}-1\right)$} & \multicolumn{2}{c}{ Occupational exposure $/\left(\mathrm{ng} \mathrm{kg} \mathrm{kw} \mathrm{day}^{-1}\right)$} \\
\cline { 2 - 4 } \cline { 4 - 5 } Thermal paper & $\mathrm{GM}$ & Median & GM & 1070 \\
Lottery tickets & 11.8 & 14.3 & 0.013 & 0.013 \\
Bus tickets & 0.013 & 0.013 & 0.001 & 0.002 \\
Business card & 0.001 & 0.002 & 0.017 & 0.018 \\
Envelopes & 0.017 & 0.018 & 0.014 & 0.014 \\
Flyer & 0.014 & 0.014 & 0.031 & 0.029 \\
Napkins & 0.031 & 0.029 & 0.011 & 0.012 \\
Newspaper & 0.011 & 0.012 & 0.022 & 0.036 \\
Printing paper & 0.022 & 0.036 & 0.015 & 0.014 \\
Food contact papers & 0.015 & 0.014 & 0.010 & 0.014 \\
Toilet papers & 0.010 & 0.014 & 0.013 & 0.014 \\
Paper towels & 0.013 & 0.014 & 0.023 & 0.025 \\
Magazine & 0.023 & 0.025 & 0.002 & 0.006 \\
\hline Total exposure $(\Sigma$ EDI) & 0.002 & 0.006 & 855 & 1070 \\
\hline
\end{tabular}

bw: body weight; GM: geometric mean.

BPA concentration in 42 supermarket receipts collected from Shenzhen, China. The estimated daily intakes (EDI) of BPA via handling of supermarket receipt for general population was of $690 \mathrm{ng} \mathrm{day}^{-1}$ (mean concentration). Liao and Kannan ${ }^{19}$ analyzed BPA concentration in 15 types of paper products $(n=202)$, including thermal receipts, flyers, magazines, tickets, mailing envelopes, newspapers, food contact papers, food cartons, airplane boarding passes, luggage tags, printing papers, business cards, napkins, paper towels, and toilet paper, collected from several cities in the USA. Thermal receipt papers were also collected from Japan, Korea, and Vietnam. The daily intake of BPA (calculated from median concentrations) through dermal absorption from handling of papers was $17.5 \mathrm{ng} \mathrm{day}^{-1}$ for the general population.

Although the EDI values calculated for BPA from paper samples were several orders of magnitude lower than the reference dose of 50,000 $\mathrm{ng} \mathrm{kg}^{-1}$ bw day ${ }^{-1}$ established by USEPA, ${ }^{38}$ other contamination sources such as food and water must also be considered. Moreover, some studies ${ }^{38-41}$ suggest that even low doses (10-100 $\mathrm{ng} \mathrm{kg}^{-1} \mathrm{bw} \mathrm{day}^{-1}$ ) of BPA can cause adverse health effects.

\section{Conclusions}

The proposed CESFS methodology for the determination of BPA is simple, fast and relatively inexpensive. These characteristics are extremely valuable for the routine analysis of numerous samples. When applied to the analysis of different types of papers frequently used in Brazil, CESFS showed statistical equivalent accuracy to LC-MS/
MS. BPA was found to be present on a scale of $\mathrm{mg} \mathrm{g}^{-1}$ in thermal papers and $\mu \mathrm{g} \mathrm{g}^{-1}$ for other paper types via both CESFS and LC-MS/MS.

\section{Acknowledgments}

This research was supported by the São Paulo Research Foundation (FAPESP, process numbers: 2014/00986-6, 2012/03465-1, 2013/23710-3, 2018/24069-3), National Council for Scientific and Technological Development (CNPq, process numbers: 154125/2018-0, 422588/2016-4 and 309822/2017-3) and INCTBio (CNPq grant No. 465389/2014-7), and Coordenação de Aperfeiçoamento de Pessoal de Nível Superior, Brazil (CAPES, finance code: 001). We are grateful for the financial support and granting of research fellowships to these funding bodies.

\section{References}

1. Vandenberg, L. N.; Maffini, M. V.; Sonnenschein, C.; Rubin, B. S.; Soto, A. M.; Endocr. Rev. 2009, 30, 75.

2. Liao, C.; Kannan, K.; Environ. Sci. Technol. 2011, 45, 6761.

3. Rochester, J. R.; Reprod. Toxicol. 2013, 42, 132.

4. Björnsdotter, M. K.; de Boer, J.; Ballesteros-Gómez, A.; Chemosphere 2017, 182, 691.

5. Hammarling, L.; Gustavsson, H.; Svensson, K.; Oskarsson, A.; Food Addit. Contam. 2000, 17, 937.

6. Liao, C.; Kannan, K.; Food Addit. Contam., Part A 2014, 31 , 319.

7. Zhou, Y.; Chen, M.; Zhao, F.; Mu, D.; Zhang, Z.; Hu, J.; Environ. Sci. Technol. 2015, 49, 7218. 
8. Yang, Y.; Lu, L.; Zhang, J.; Yang, Y.; Wu, Y.; Shao, B.; J. Chromatogr. A 2014, 1328, 26.

9. Wu, S.-Y.; Xu, Q.; Chen, T.-S.; Wang, M.; Yin, X.-Y.; Zhang, N.-P.; Shen, Y.-Y.; Wen, Z.-Y.; Gu, Z.-Z.; Chin. J. Anal. Chem. 2010, 38, 503.

10. Schecter, A.; Malik, N.; Haffner, D.; Smith, S.; Harris, T. R.; Paepke, O.; Birnbaum, L.; Environ. Sci. Technol. 2010, 44, 9425.

11. Guart, A.; Bono-Blay, F.; Borrell, A.; Lacorte, S.; Food Addit. Contam., Part A 2011, 28, 676.

12. Geens, T.; Apelbaum, T. Z.; Goeyens, L.; Neels, H.; Food Addit. Contam., Part A 2010, 27, 1627.

13. Biedermann, S.; Tschudin, P.; Grob, K.; Anal. Bioanal. Chem. 2010, 398, 571 .

14. Eckardt, M.; Kubicova, M.; Tong, D.; Simat, T. J.; J. Chromatogr. A 2020, 1609, 460437.

15. Lu, S. Y.; Chang, W. J.; Sojinu, S. O.; Ni, H. G.; Chemosphere 2013, 92, 1190 .

16. Geens, T.; Goeyens, L.; Kannan, K.; Neels, H.; Covaci, A.; Sci. Total Environ. 2012, 435-436, 30.

17. Mendum, T.; Stoler, E.; Vanbenschoten, H.; Warner, J. C.; Green Chem. Lett. Rev. 2011, 4, 81.

18. Rocha, B. A.; Azevedo, L. F.; Gallimberti, M.; Campiglia, A. D.; Barbosa, F.; J. Toxicol. Environ. Health, Part A 2015, 78, 1181.

19. Liao, C.; Kannan, K.; Environ. Sci. Technol. 2011, 45, 9372.

20. Russo, G.; Barbato, F.; Grumetto, L.; Sci. Total Environ. 2017, 599-600, 68.

21. Pakalin, S.; Aschberger, K.; Munn, S.; Olsson, H.; Pakalin, S.; Pellegrini, G.; Vegro, S.; Paya Perez, A. B.; European Union Risk Assessment Report - Human Health Addendum of April 2008 - 4,4'-Isopropylidenediphenol (Bisphenol-A) - Part 2 Human Health; Publications Office of the European Union: Italy, 2010. Available at https://ec.europa.eu/jrc/en/publication/ eur-scientific-and-technical-research-reports/european-unionrisk-assessment-report-human-health-addendum-april-2008-44, accessed in June 2020.

22. Gehring, M.; Tennhardt, L.; Vogel, D.; Weltin, D.; Bilitewski, B. In Waste Management and the Environment II, WIT Transactions on Ecology and the Environment, vol. 78; Brebbia, C. A.; Kungulos, S.; Popov, V.; Itoh, H., eds.; WIT Press: Southampton, Boston, 2004, p. 294.

23. Wang, H.; Zou, Y.; Li, C.; Wang, W.; Zhang, M.; Dahlgren, R. A.; Wang, X.; J. Fluoresc. 2013, 23, 1157.

24. Zhuang, Y. F.; Cao, G. P.; Mao, J. Y.; Liu, B. L.; J. Appl. Spectrosc. 2019, 85, 1094.

25. Ng, C. M.; Reuter, W. M.; Analysis of Bisphenol A in Toys by HPLC with Fluorescence Detection; PerkinElmer, Inc.: Waltham, MA, USA, 2008. Available at https://www. perkinelmer.com/lab-solutions/resources/docs/APP_Analysisof-Bisphenol-A-in-Toys-012153_01.pdf, accessed in June 2020.

26. Lateef, S. S.; Analysis of Bisphenol A Leaching from Baby
Feeding Bottles; Agilent Technologies: Santa Clara, CA, USA, 2017.

27. Campiglia, A. D.; Bystol, A. J.; Yu, S.; Anal. Chem. 2006, 78, 484.

28. Santos, M.; Roy, B. C.; Goicoechea, H. C.; Campiglia, A. D.; Mallik, S.; J. Am. Chem. Soc. 2004, 126, 10738.

29. Goicoechea, H. C.; Yu, S.; Moore, A. F. T.; Campiglia, A. D.; Talanta 2012, 101, 330.

30. Vatsavai, K.; Goicoechea, H. C.; Campiglia, A. D.; Anal. Biochem. 2008, 376, 213.

31. Liao, C.; Liu, F.; Kannan, K.; Environ. Sci. Technol. 2012, 46, 6515 .

32. Lassen, C.; Mikkelsen, S. H.; Brandt, U. K.; Migration of Bisphenol A from Cash Register Receipts and Baby Dummies; The Danish Environmental Protection Agency: Odense, 2011, available at http://www2.mst.dk/udgiv/ publications/2011/04/978-87-2708-93-9.pdf accessed in June 2020.

33. https://www.ewg.org/research/bpa-in-store-receipts accessed in June 2020.

34. https://docplayer.se/4754572-Bisfenol-a-i-svenska-kvitton.html accessed in June 2020.

35. Vinggaard, A. M.; Körner, W.; Lund, K. H.; Bolz, U.; Petersen, J. H.; Chem. Res. Toxicol. 2000, 13, 1214.

36. Ozaki, A.; Yamaguchi, Y.; Fujita, T.; Kuroda, K.; Endo, G.; Food Chem. Toxicol. 2004, 42, 1323.

37. Instituto Brasileiro de Geografia e Estatística (IBGE); Pesquisa de Orçamentos Familiares 2008-2009, Análise do Consumo Alimentar Pessoal no Brasil; IBGE: Rio de Janeiro, 2010. Available at https://biblioteca.ibge.gov.br/visualizacao/livros/ liv50063.pdf, accessed in June 2020.

38. U.S. Environmental Protection Agency (US EPA); EPA/600/R06/096F Child-Specific Exposure Factors Handbook; National Center for Environmental Assessment, Office of Research and Development: Washington, DC, 2008, available at https://cfpub. epa.gov/ncea/risk/recordisplay.cfm?deid=199243 accessed in June 2020.

39. Cabaton, N. J.; Canlet, C.; Wadia, P. R.; Tremblay-Franco, M.; Gautier, R.; Molina, J.; Sonnenschein, C.; Cravedi, J. P.; Rubin, B. S.; Soto, A. M.; Zalko, D.; Environ. Health Perspect. 2013, 121, 586.

40. Carchia, E.; Porreca, I.; Almeida, P. J.; D’Angelo, F.; Cuomo, D.; Ceccarelli, M.; de Felice, M.; Mallardo, M.; Ambrosino, C.; Cell Death Dis. 2015, 6, e1959.

41. Vandenberg, L. N.; Ehrlich, S.; Belcher, S. M.; Ben-Jonathan, N.; Dolinoy, D. C.; Hugo, E. R.; Hunt, P. A.; Newbold, R. R.; Rubin, B. S.; Saili, K. S.; Soto, A. M.; Wang, H.-S.; vom Saal, F. S.; Endocr. Disruptors 2013, 1, e26490.

Submitted: March 1, 2020

Published online: June 17, 2020 